\title{
Development of EPABX System Using Internet Protocol
}

\author{
Parmar B.P., PIET; Mary G.S.; Gohil R., AMUL
}

\begin{abstract}
In this 21st century, we are living in the world of science \& technology. Due to rapid growth in the field of industries, large amount of communication is required between the inter-departments of a particular industry for obtaining all information regarding a particular product from its manufacturing point to the delivery of that particular product to the customers.

So with respect to the previous scenario in large scale industries a system was developed for solving the problems of internal \& external communication in a industry with its several other branches which are located at a far distances in nationwide. The system used was C-DOT 256 PORT RURAL AUTOMATIC EXCHANGE (ABBREVIATED AS C-DOT 256P RAX). This system was designed to suit the distinctive needs of developing countries like India.

In our organisation we need 312 port line. Due to this limitation we introducing new system called INTERNET PROTOCOL BASED EPABX. In this system we can use 1064 ports for the communication purpose and with this system we will be able to increase the number of users and reduce the call rates.
\end{abstract}

\section{Introduction}

The C-DOT 256 Rural Automatic Exchange (RAX) is a digital Stored Program Controlled (SPC) switching system with a capacity of 256 terminations. These terminations include subscriber lines, trunks to other exchanges and tones.

256 ports which include terminal circuits and service circuits. Out of 256 ports, 24 ports are reserved for service circuits and cannot be used for subscriber lines or trunks (16 ports for tones and announcements (two RAT cards) and 8 ports are occupied by one RTC).Remaining 232 ports can be assigned to different combinations of Conference Card, Analog, Digital Trunk Cards and MF cards.

In C-DOT system only 232 ports are available for user but we require more than 232 ports so we need some upgrading technology. In C-DOT system. also analog DID is used but BSNL suggest us to switch over from analog DID to Digital DID. Because if any kind of technical problem occur the spareparts is not available of analog DID. There is trunking problem in C-DOT system. C-DOT works on analog system and CLI(Caller Line Identification) is not working on analog system. Due to this limitation we are switching towards EPABX system.

In this system we are using 1 MMD(Master Mother Board) and 4 EMD(Extended Mother Board). In this system there are 1024 port are available. 4 EMD are connected with MMD using IP(Internet Protocol). Subscriber line card are connected on slot no.4 for increase users. Other slots are for trunk card, external music card , voise mail card, Digital station Card and etc. LCR(Least Call Routine) card are interface with main MMD for find the cheapest route.

\section{Global Digital System-600}

The GDS-600 is an advanced ISDN Digital hybrid telephone system employing a microprocessor stored program and digitally controlled solid state Time-division switching. The GDS-600 system is specifically designed for small business as well as residential applications.

At the forefront of the system design is a universal concept to adapting and connecting with a variety of communications devices. Productive HYBREX Digital Key Telephones offer thoughtfully designed productive feature access to keep you connected with one another and customers. Auto Telecom technology leads the industry in providing for compatibility with devices such as fax machines, answering machines, cordless phones, computer modems and other office/home equipment. 


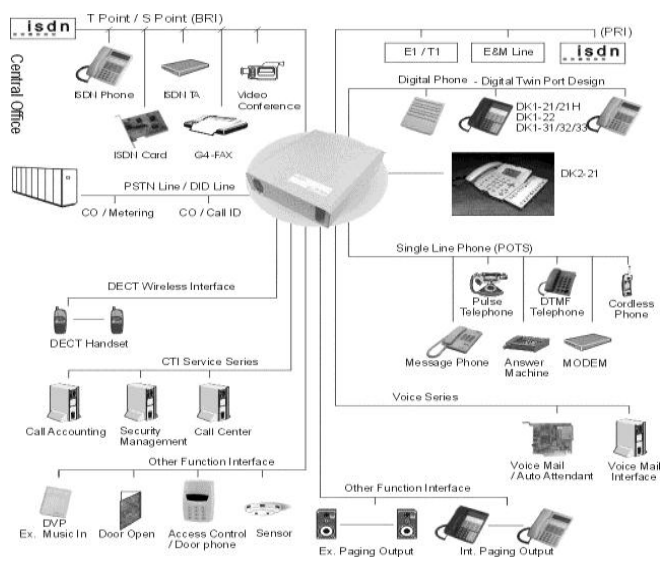

Figure 1:Global Digital System

Key highlights of the GDS-600 series include:

- Liquid Crystal Display

- $\quad$ Full ISDN features

- Digital Twin Port

- Varied Extension Alternatives

- Flexibility of System Applications

- $\quad$ Easy Maintenance

- Easy Installation

- Economy and Efficiency

\section{Subscriber Line Card}

The subscriber line circuit card for this distributed control system is outlined. The local processor is a single chip microprocessor controlling only one line card. This card would serve from four to thirty-two subscriber lines, although a maximum of sixteen per card is considered optimal. The local processor could be shared over several line cards, but this requires extra backplane wiring to interconnect the local processor and the circuit cards it controls.

Between the per line SLIC,CODEC and filter components of the card and the serial TDM highways of the line switch group is the TP3110 or TP3120 Digital Line Interface Controller (DLIC). Either device functions as the first stage ofspace and time switching for the line switch group. It controls PCM, data and control communications between the system TDM serial highways, the per line CODEC, filter and SLIC circuits (or other subscriber line and special service circuit devices) and the single-chip microprocessor.

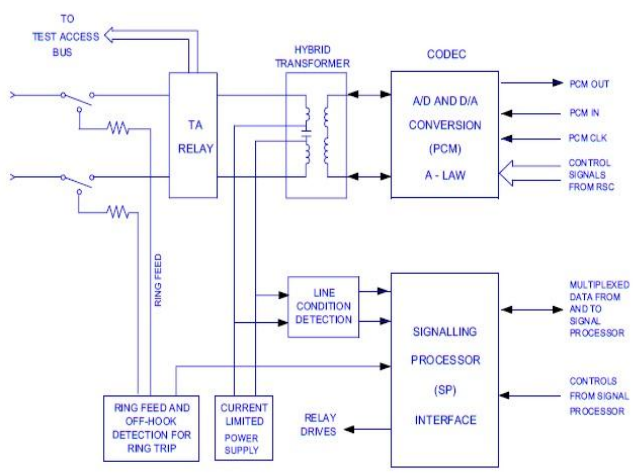

Figure 2 Block Diagram Of Line Card

The DLIC contains two internal busses. The first is the data transport bus between the CODEC interface port and the two or four serial port transceivers. It operates in synchronism with the serial highway master clock. PCM, subscriber and signaling data are transferred through the DLIC via this bus. Control is maintained by way of instructions loaded in the on-chip time slot map memory.

The second internal bus is used exclusively by the local processor. Through this bus, the processor clears and loads the time slot map, sends or receives control information for any line circuit device and com- 
municates line card control information to and from the central system processor. Data transfers between the synchronous and asynchronous busses are controlled by special time slot map instructions, a bus-to-bus interface register and the vectored interrupt structure of the DLIC.

\section{Main Distribution Frame}

A main distribution frame (mdf) is a signal distribution frame or cable rack used in telephony to interconnect and manage telecommunication wiring between itself and any number of intermediate distribution frames and cabling from the telephony network it supports.

The mdf connects equipment inside a telecommunications facility to cables and subscriber carrier equipment. Every cable that supplies services to user telephones lines ends up at an mdf and is distributed through mdf to equipment within local exchanges.

An mdf can provide flexibility in assigning telecommunications facilities at a lower cost and higher capacity than a patch panel. The most common kind of mdf is a long steel rack that is accessible from both sides. Termination blocks are arranged horizontally on one side at the front of the rack shelves. The jumpers lie on the shelf and move through a steel hoop in order to run through vertically arranged termination blocks.

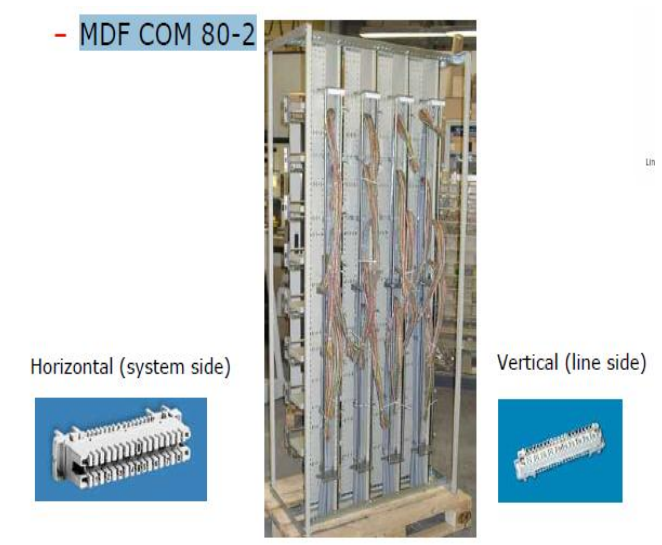

Figure 3 Main Frame Distribution 80-2

A typical mdf can hold hundreds of thousands of jumpers and dozens of them can be changed every day for decades without tangling when administered by experienced professionals. Jumpers are twisted pairs of cable, each one corresponding to an individual telephoneline.

Mdfs are single-sided so that the workers can install, remove or change jumpers. However,old manual jumpering systems are now mostly automated using automated main distribution frames. Computer systems that control mdf operations assign terminals close to one another so that jumpers need not be long and shelves are not congested with wires as the jumpers are shorter.

\begin{tabular}{|c|c|c|c|c|c|c|}
\hline & HVt 71 & HVt 91M & $\mathrm{HVt}$ & $\mathrm{HVt}$ & $\mathrm{HVt}$ & $\mathrm{HVt}$ \\
\hline & & & COM 91-2 & $\begin{array}{l}\text { COM B2- } \\
2\end{array}$ & $\begin{array}{l}\text { COM 80- } \\
2\end{array}$ & $\begin{array}{l}\text { COM 80- } \\
1\end{array}$ \\
\hline MDF & \multicolumn{2}{|c|}{ for system 71} & & \multicolumn{2}{|c|}{ for LSA-PROFIL } & $\begin{array}{l}\text { for LSA- } \\
\text { PLUS }\end{array}$ \\
\hline $\begin{array}{l}\text { Exchange } \\
\text { type }\end{array}$ & $\begin{array}{l}\text { analog } \\
\text { and } \\
\text { digital } \\
\text { exchange }\end{array}$ & $\begin{array}{l}\text { computer } \\
\text { controlled } \\
\text { exchange } \\
\text { and } \\
\text { switchboard }\end{array}$ & $\begin{array}{l}\text { computer } \\
\text { controlled } \\
\text { exchange } \\
\text { and } \\
\text { switchboard }\end{array}$ & $\begin{array}{l}\text { computer } \\
\text { controlled } \\
\text { exchange }\end{array}$ & $\begin{array}{l}\text { analog } \\
\text { and } \\
\text { digital } \\
\text { exchange }\end{array}$ & $\begin{array}{l}\text { analog } \\
\text { and } \\
\text { digital } \\
\text { exchange }\end{array}$ \\
\hline $\begin{array}{l}\text { exchange } \\
\text { size }\end{array}$ & $\begin{array}{l}\text { big and } \\
\text { middle } \\
\text { Exchange }\end{array}$ & $\begin{array}{l}\text { big and } \\
\text { small } \\
\text { Exchange }\end{array}$ & $\begin{array}{l}\text { big and } \\
\text { small } \\
\text { Exchange }\end{array}$ & $\begin{array}{l}\text { big and } \\
\text { middle } \\
\text { Exchange }\end{array}$ & $\begin{array}{l}\text { big and } \\
\text { middle } \\
\text { Exchange }\end{array}$ & $\begin{array}{l}\text { big and } \\
\text { middle } \\
\text { Exchange }\end{array}$ \\
\hline $\begin{array}{l}\mathrm{HVt} \\
\text { allocation } \\
\text { system } \\
\text { side } \\
\text { Line side }\end{array}$ & $\begin{array}{l}\text { vertical } \\
\text { vertical }\end{array}$ & $\begin{array}{l}\text { vertical } \\
\text { vertical }\end{array}$ & $\begin{array}{l}\text { vertical } \\
\text { vertical }\end{array}$ & $\begin{array}{l}\text { vertical } \\
\text { vertical }\end{array}$ & $\begin{array}{l}\text { Horizontal } \\
\text { vertical }\end{array}$ & $\begin{array}{l}\text { Horizontal } \\
\text { vertical }\end{array}$ \\
\hline Capacity & $\begin{array}{l}\text { pairs:pairs } \\
480: 600\end{array}$ & $\begin{array}{l}\text { pairs:pairs } \\
512: 600\end{array}$ & $\begin{array}{l}\text { pairs:pairs } \\
512: 600\end{array}$ & $\begin{array}{l}\text { pairs:pairs } \\
512: 600\end{array}$ & $\begin{array}{l}\text { pairs:pairs } \\
576: 600\end{array}$ & $\begin{array}{l}\text { pairs:pairs } \\
576: 600\end{array}$ \\
\hline $\begin{array}{l}\text { frame } \\
\text { type }\end{array}$ & $\begin{array}{l}\text { vertical } \\
\text { horizontal }\end{array}$ & Vertical & Vertical & Vertical & $\begin{array}{l}\text { vertical } \\
\text { horizontal }\end{array}$ & . \\
\hline
\end{tabular}

Table 2: Different Types Of Mfd 


\section{Conclusion}

A proposal for replacing the existing switching based trunk system which had the limitation of less number of subscribers -192 is proposed to be implemented .The new system will be capable of handling 1024 subscriber.

\section{Future work}

For interfacing with GDS motherboard we require Line card. By developing line card we directly give the information to the Trunk Line .so complexity is reduce. After developing EPABX system we get information of caller and also recording facility available and many more.

\section{Acknowledgments}

We are thankful to IOSR Journal for the support to develop this document.

\section{References}

[1] J.Kalyan Prasad, B.Anil Kumar. Analysis of SIP and Realization of Advanced IP-PBX features. (978-1-4244-8679-3/11/\$26.00 (C)2011 IEEE.

[2] LIU, Q. F., ZHOU, H. H., and QIN, Y. J., "Design and Implementation of SIP Phone Based on SCTP and DCCP", Telecommunication Engineering, 48, 1, January 2008, pp. 32-36.

[3] ZHANG, B. C., HE, Q. L., and QU, K., "The Design and Realization of Distance Teaching System Based on SIP Protocol", Microelectronics \& Computer, 24, 3, March 2007, pp. 150-153.

[4] Lu, W., Zeng, W. H., "The Research of Asterisk-An Open Source PBX",Computer Systems Applications, February 2007, pp. 8083.

[5] J. Saldaña, J. Aznar, E. Viruete, J. Fernández-Navajas and J. Ruiz-Mas, “QoS Measurement-Based CAC for an IP Telephony system", QShine2009,

[6] The Sixth International ICST Conference on Heterogeneous Networking for Quality, Reliability, Security and Robustness, Las Palmas de Gran Canaria (Spain), Nov. 2009.

[7] Yamamoto et al.(2008). Validation of VoIP System for University Network, Proceedings of ICACT2008, 9C-2, Phoenix Park, Feb.2008,Korea.

[8] R.Sparks,A.Johnston,D.Petrie, Session Initiation Protocol Call Control-Transfer, RFC 5589, June 2009. 